\title{
An Electrophysiological and Behavioural Study of Self-Stimulation in the Orbitofrontal Cortex of the Rhesus Monkey
}

\author{
F. MORA,${ }^{1}$ D. B. AVRITH ${ }^{2}$ AND E. T. ROLLS ${ }^{3}$ \\ University of Oxford, Department of Experimental Psychology \\ South Parks Road, Oxford OX1 3UD, England
}

Received 2 April 1979

\begin{abstract}
MORA, F., D. B. AVRITH AND E. T. ROLLS. An electrophysiological and behavioural study of self-stimulation in the orbitofrontal cortex of the rhesus monkey. BRAIN RES. BULL 5(2) 111-115, 1980.- It was found that neurons in the posterior orbitofrontal cortex, area 13, of the rhesus monkey were activated from self-stimulation electrodes (in 142 of 168 possible instances), and that neurons in the anterior orbitofrontal areas were much less likely to be activated from the self-stimulation electrodes (in only 28 of 177 possible instances). This activation of neurons in the posterior orbitofrontal cortex was found mainly from self-stimulation sites in the nucleus accumbens septi, lateral hypothalamus, and the orbitofrontal cortex itself. In a second investigation the orbitofrontal cortex was mapped for self-stimulation, and it was found that self-stimulation occurred in the posterior orbitofrontal area. These results implicate the posterior or caudal orbitofrontal cortex, mainly area 13 , but not the more anterior orbitofrontal areas, in self-stimulation.
\end{abstract}

Orbitofrontal cortex Frontal cortex Self-stimulation Brain-stimulation reward

THERE is now considerable evidence that self-stimulation occurs in parts of the prefrontal cortex [19,21], and neurons in the sulcal and the medial prefrontal cortex are activated from self-stimulation sites in the hypothalamus and related areas $[2,17,18]$. In the monkey, fibres from self-stimulation sites along the course of the medial forebrain bundle project to the orbitofrontal cortex [20] (a region of frontal cortex which may correspond to sulcal prefrontal cortex in the rat-[3]), and self-stimulation of the caudal orbitofrontal cortex has been found in the squirrel monkey and the rhesus monkey [9, $12,13,16]$. Further, neurons in the orbitofrontal cortex of the rhesus and squirrel monkey are activated by selfstimulation of at least some self-stimulation sites [13, 16, 17]. Given that these findings were on the caudal orbitofrontal cortex, and because of current interest in the function of the frontal cortex and its dopaminergic inputs $[1,8,9]$ the investigations described here were performed. First, the entire orbitofrontal cortex was mapped for self-stimulation sites in the rhesus monkey. Second, recordings were made throughout the orbitofrontal cortex to determine within which area neurons were activated from self-stimulation sites.

\section{METHOD}

\section{Animals and General Procedure}

Four rhesus monkeys weighing $2.5-3.5 \mathrm{~kg}$ were implanted under Nembutal anaesthesia with monopolar self-stimulation electrodes made of 00 gauge stainless-steel insect pins insulated to within $0.5 \mathrm{~mm}$ of the tip. The electrodes were held in insulating bushes in a platform made of stainless-steel, and implanted in the orbitofrontal cortex, caudate nucleus, amygdala, and lateral hypothalamus (two monkeys), and orbitofrontal cortex, caudate nucleus, nucleus accumbens septi, amygdala, lateral hypothalamus, substantia nigra and vental tegmental area (two monkeys), using the atlas of Snider and Lee [22]. The top of each electrode was bent and attached to an Amphenol socket holder which was held at a distance in order to permit single unit recordings ipsilateral to the stimulating electrodes. Access for the recordings was via a stainless-steel well attached to the platform above the orbitofrontal cortex.

\section{Self-Stimulation Procedure}

Monophasic, $0.5 \mathrm{msec}$, negative, rectangular, capacitatively coupled pulses at a frequency of $100 \mathrm{~Hz}$ in trains lasting $0.3 \mathrm{sec}$ were applied to the electrode under test when the monkey contacted the bar in front of him. (Pulse trains were generated with a Grass $\mathbf{S 8}$ stimulator followed by a Grass SIU5 stimulus isolation unit.) Current return was via the screws permanently implanted in the skull. The current of the constant current stimulation pulses was monitored continuously with a Tektronix 502A oscilloscope. When self-stimulation was found at a particular site, a rate-

${ }^{1}$ Departamento de Fisiologia Facultad de Medicina, Universidad de Granada, Granada, Spain.

${ }^{2} \mathrm{C} / \mathrm{o}$ University of Cambridge, Physiological Laboratory, Downing Street, Cambridge, CB2 3E6, England.

${ }^{3}$ Correspondence should be addressed to: Dr. E. T. Rolls, Department of Experimental Psychology, University of Oxford, South Parks Road, Oxford 0X1 3UD, England. 
intensity curve was repeated over several days. The current for self-stimulation was set to be at the middle point in the rate-intensity curve, during the neurophysiological recordings. An example of the rate-current intensity curves for these animals is shown elsewhere [6].

\section{Recording of Single Unit Activity}

Single unit activity was recorded extra-cellularly with glass-coated tungsten microelectrode (made using a method developed by S. J. Judge and E. T. Rolls based on the method described by Merrill and Ainsworth, [4], but without platinum plating). The recordings were made in the course of a related investigation [6] using a Trent Wells' stereotaxic micropositioner, attached each day to the chronically implanted stainless-steel well above the orbitofrontal cortex, and the electrodes were lowered into the brain using a hydraulic microdrive mounted on the micropositioner. The stereotaxic co-ordinates for the microelectrode for each track aimed at the orbitofrontal cortex were set up with a dummy implant. The co-ordinates for each track were confirmed using two X-rays taken in the antero-posterior and lateral axes at the end of each track, and were related to the positions of nearby stimulation electrodes, the sites of which were localised histologically. In addition, microlesions were made through the recording electrodes on some tracks to allow direct histological verification of the recording sites. Electrical activity was passed through a unity gain FET system mounted on the microdrive, amplified conventionally, displayed on an oscilloscope (Tektronix 564B), and stored on magnetic tape (Revox A77).

To analyse whether individual neurons in the orbitofrontal cortex were influenced by self-stimulation, current pulses were applied to each of the self-stimulation electrodes at the self-stimulation current intensity, and the presence of activation, or of inhibition of spontaneous activity, was measured conventionally as described elsewhere $[11,12,13,14$, 16]. In particular, units which fired one or several times following a stimulation pulse with a latency of 2-50 msec, and a latency which varied over $0.5 \mathrm{msec}$, were classed as transsynaptically driven. If units fired with short, fixed, latencies, (e.g. $2-10 \mathrm{msec}$ ), then these were classed as directly excited by the stimulation pulses, and tests for collision to prove antidromic activation were attempted (see [11]). Stimulation was applied regularly from each of the electrodes in sequence while the microelectrode was being lowered, to ensure that neurons activated from any of the electrodes, including neurons without spontaneous activity, would be detected. Stimulation at sites at which no self-stimulation had been obtained was also included in the sequence, to allow comparison of effects obtained from self-stimulation and non self-stimulation sites. The currents used at the sites negative for self-stimulation were those which just elicited a behavioral motor response. Differential recordings (relative to a nearly indifferent electrode) were made to minimize stimulus artifact, in order to ensure that short latency neuronal activation could be seen.

\section{RESULTS}

Activation of Neurons in the Orbitofrontal Cortex during Self-Stimulation of Different Brain Sites

In the orbitofrontal cortex of the three animals 296 cells activated from the different self-stimulation sites were analysed. The main self-stimulation sites (shown in Fig. 2)

\section{TABLE 1}

ACTIVATION OF NEURONS IN THE ORBITOFRONTAL CORTEX FROM SELF-STIMULATION SITES IN THE ORBITOFRONTAL CORTEX (OF), LATERAL HYPOTHALAMUS (LH), AMYGDALA (AMY), CAUDATE NUCLEUS (CA), NUCLEUS ACCUMBENS (NAS), AND REGION OF THE SUBSTANTIA NIGRA (SN)

\begin{tabular}{|c|c|c|c|c|c|c|}
\hline $\begin{array}{l}\text { Recording } \\
\text { site }\end{array}$ & OF & OF & OF & OF & OF & OF \\
\hline \multicolumn{7}{|l|}{ Stimulation } \\
\hline $\begin{array}{l}\text { Number of } \\
\text { animals }\end{array}$ & 2 & 3 & 1 & 2 & 1 & 1 \\
\hline \multicolumn{7}{|l|}{$\begin{array}{l}\text { Latency } \\
\text { (msec) }\end{array}$} \\
\hline $2 \mathrm{D}$ & 2 & & & & 3 & \\
\hline $2 S$ & 10 & 2 & & & 1 & \\
\hline \multicolumn{7}{|l|}{$4 \mathrm{D}$} \\
\hline $\begin{array}{l}4 S \\
6 D\end{array}$ & \multicolumn{5}{|c|}{$6 \mathrm{D}$} & 3 \\
\hline $6 S$ & 14 & 1 & & & & \\
\hline 8 & 18 & 1 & & & 6 & 2 \\
\hline 10 & 21 & 1 & & 2 & 20 & \\
\hline 12 & 4 & 3 & & 1 & 12 & \\
\hline 14 & 5 & 1 & & & 9 & \\
\hline 16 & & 1 & & & & 1 \\
\hline 18 & & 3 & & & 7 & \\
\hline 20 & 12 & 7 & 1 & 1 & 22 & \\
\hline 22 & 2 & 3 & & & 3 & \\
\hline 24 & 1 & 2 & & & 15 & \\
\hline 26 & 2 & & & & & \\
\hline 28 & & & & & 1 & \\
\hline 30 & 8 & 2 & 3 & & 7 & \\
\hline 40 & 5 & 1 & & 1 & 12 & \\
\hline 50 & 2 & 1 & 2 & & 1 & \\
\hline 60 & & & & & 2 & \\
\hline \multicolumn{7}{|l|}{70} \\
\hline \multicolumn{7}{|l|}{80} \\
\hline Undetermined & 3 & & & & & \\
\hline Total & 125 & 31 & 6 & 5 & 141 & 6 \\
\hline \multicolumn{7}{|l|}{ Median } \\
\hline latency & 8 & 18 & & & 20 & \\
\hline
\end{tabular}

The numbers of neurons activated with different latencies are shown. Sume directly activated neurons (D), as opposed to the synaptically activated neurons (S) elsewhere in the table, are indicated separately.

from which the activation occurred were the orbitofrontal cortex, the nucleus accumbens, and the lateral hypothalamus. The median latency of activation from these sites is shown in Table 1. Although activation from other self-stimulation sites such as the caudate nucleus and substantia nigra was seen, this was infrequent and the total number of units recorded from these sites did not allow accurate estimation of the median latency. Eleven neurons showed convergent activation from two self-stimulation sites, primarily from the orbitofrontal cortex and nucleus accumbens, and three more neurons showed convergent activation from more than two sites, from the lateral hypothalamus, nucleus accumbens and caudate nucleus. Activation was almost entirely transsynaptic, but two cells were directly driven from the orbitofrontal cortex and three 


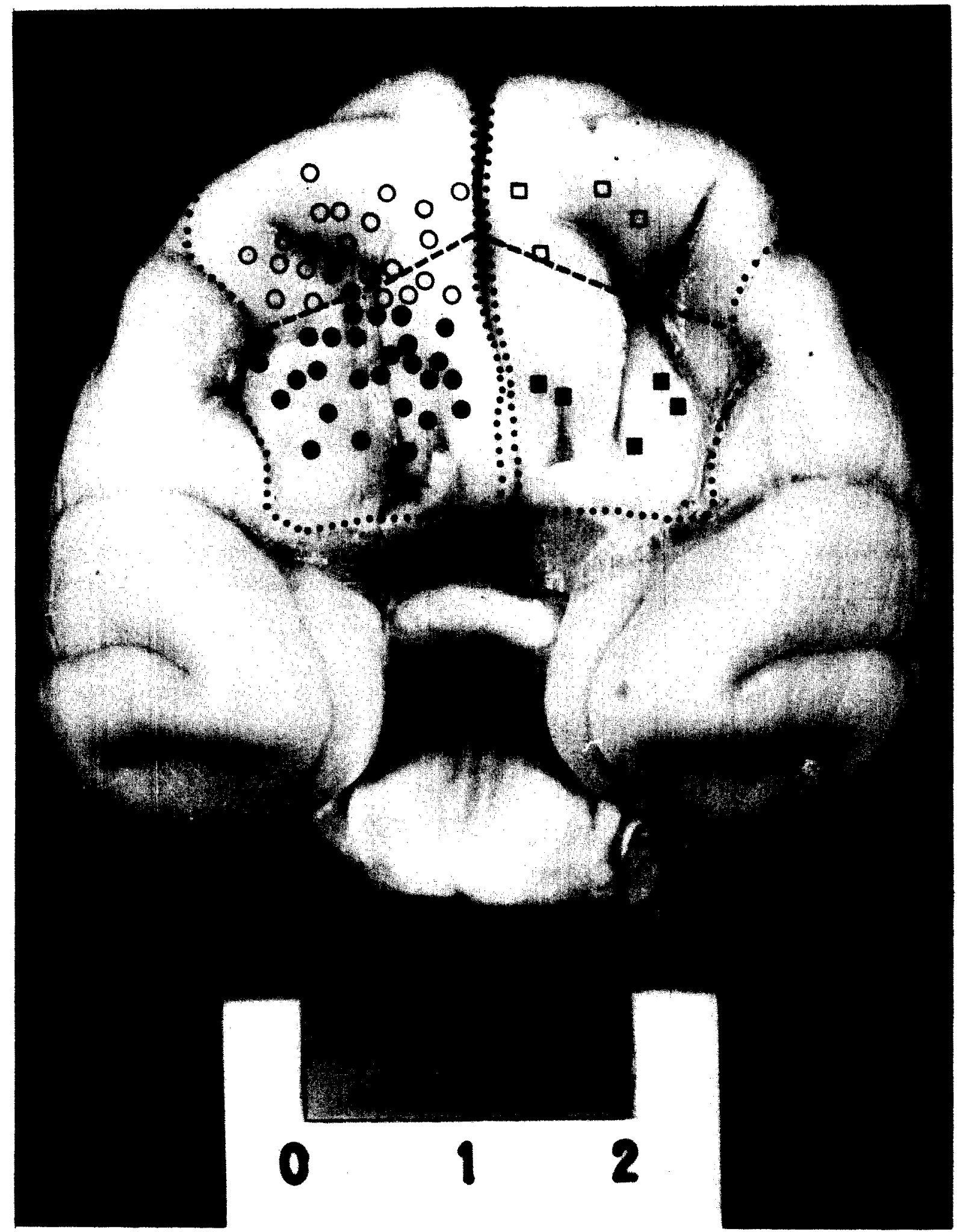

FIG. 1. The orbitofrontal surface of rhesus monkey brain 23. Left side. Positions of microelectrode tracks on which single neurons were activated (solid circles, $\bullet$ ), or were not activated (open circles, $O$ ) from self-stimulation sites. Right side. Sites at which self-stimulation was (solid squares, $\square$ ), or was not (open squares, $\square$ ), obtained. The dashed line separates posterior from anterior orbitofrontal areas and encloses areas 13 and 14 posteriorly. The scale is in $\mathrm{cm}$. 
TABLE 2

ACTIVATION OF NEURONS IN 2 DIFFERENT ORBITOFRONTAL AREAS FROM ELECTRODES POSITIVE OR NEGATIVE FOR SELFSTIMULATION IN THE LATERAL HYPOTHALAMUS (HL), CAUDATE NUCLEUS (CA), REGION OF THE SUBSTANTIA NIGRA (SN), NUCLEUS ACCUMBENS (NAS), AMYGDALA (AMY), AND BRAINSTEM (LC)

\section{Orbitofrontal cortex area}

Area 13

Anterior

orbitofrontal

areas

Number of cells driven from positive self-stimulation sites
$\mathrm{HL}$

CA

SN

NAS

20

3

6

113

142

Total

Number of cells driven from negative self-stimulation sites

$\begin{array}{ccc}\text { LC } & 1 & 0 \\ \text { AMY } & 5 & 2 \\ \text { SN } & 3 & 3 \\ \text { Total } & 9 & 5\end{array}$

Number of cells not driven

Total
1

0

27

28
5

144

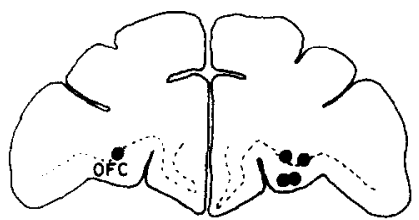

Orbitafrontal Cortex

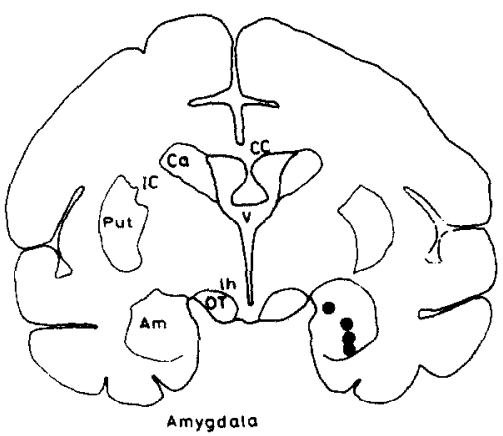

from the nucleus accumbens septi, and collision proving antidromic activation was demonstrated in one.

The cells described above were mainly in the posterior orbitofrontal cortex, but in monkey number 23 a systematic mapping study was included in order to explore the entire orbitofrontal area for activation of cells from different stimulation sites. Figure 1 (left side) shows a summary of that study and represents the recording tracks in which cells were activated $(\bullet)$ or were not activated $(0)$ from self-stimulation sites (see also table 2). It seems clear that the area activated from self-stimulation sites outside the orbitofrontal cortex is mainly area 13 of the orbitofrontal cortex with possibly some activation medial to area 13 in area 14 [23]. The rest of the orbitofrontal cortex (mainly areas 10 and 11) showed very little activation during self-stimulation of the sites tested, although many cells not activated from the self-stimulation electrodes were recorded. Extracting data from Table 2, it is clear that in area 13,142 instances of activation of neurons from self-stimulation sites were found in a sample size of 168 , and that in the anterior orbitofrontal areas, only 28 instances of activation of neurons from self-stimulation sites were found in a sample size of $177\left(\chi^{2}=56, \mathrm{df}=1, \mathrm{p}<0.001\right)$. Thus cells in area 13 are more likely than cells in the anterior orbitofrontal areas to be activated from the self-stimulation sites used in this investigation.

\section{Self-Stimulation in the Orbitofrontal Cortex}

Self-stimulation was obtained in every animal in area 13. Moreover, in monkey 23 a mapping study for self-stimulation of the orbitofrontal cortex was also performed using microelectrodes driven by the microdrive. Figure 1 (right side) shows the positive and negative points for self-stimulation. Self-stimulation was obtained in area 13 (with some medial

FIG. 2. Examples of the self-stimulation sites in the rhesus monkeys. (Am-amygdala; Ca-Caudate nucleus; CC-Corpus Callosum; HI-Hippocampus; IC-Internal Capsule; lh-Lateral hypothalamus; NAS-Nucleus accumbens; OFC-Orbitofrontal Cortex; $1 \mathrm{~g}-$ Lateral geniculate nucleus; OT-Optic Tract; Put-Putamen; sn-Substantia nigra; TC-Tail of Caudate Nucleus; th-thalamus; TPTemporal Pole; V-Ventricle). 
points in area 14) (the region where cells were activated from other self-stimulation sites) but was not obtained in points in more anterior orbitofrontal areas (where cells were not activated from self-stimulation sites). The characteristics of and factors which influence self-stimulation in area 13 have been described elsewhere [6].

\section{DISCUSSION}

The present study shows that self-stimulation of the orbitofrontal cortex and activation of neurons in the orbitofrontal cortex by self-stimulation of other brain regions is restricted to the most posterior or caudal region (mainly area 13 of Walker). The fact that both self-stimulation and the activation of neurons during self-stimulation are found together in area 13 but not in more anterior areas of the orbitofrontal cortex suggest strongly that only the posterior region, mainly area 13 , is involved in self-stimulation of the orbitofrontal cortex.

The neurons in the orbitofrontal cortex were mainly activated by self-stimulation of the nucleus accumbens septi, lateral hypothalamus, and orbitofrontal cortex itself, although cells were also found to be activated from other self-stimulation sites such as the caudate nucleus and region of the substantia nigra. It is of interest that firstly, anatomical anterograde degeneration studies indicate a connection from the orbitofrontal cortex of the monkey to the nucleus accumbens septi and lateral hypothalamus [10]. Secondly, le- sions in self-stimulation sites in the medial forebrain bundle produce fibre degeneration directed to the orbitofrontal cortex in the monkey [20]. Thirdly, similar results to those reported here in the primate have been found for selfstimulation of the sulcal prefrontal cortex of the rat $[17,18]$, an area which may correspond to the orbitofrontal cortex of the monkey [3].

It was not common to find convergent activation from different self-stimulation sites on to single neurons in the orbitofrontal cortex. For comparison, much more convergence is found onto neurons in the lateral hypothalamus [16], suggesting that the orbitofrontal cortex may subserve a different function to that of the lateral hypothalamus in self-stimulation (see $[13,14,16]$ ).

At present it is not possible to draw a correlation between self-stimulation of the orbitofrontal cortex and dopamine innervation in the primate, as has been done for instance in the prefrontal cortex of the rat [5]. It would be very interesting to investigate iontophoretically whether neurons in area 13 of the primate activated from self-stimulation sites are influenced by dopamine, and to compare this with neurons in more anterior areas.

In conclusion the experiments presented in this paper show neuro-physiologically and behaviorally that the orbitofrontal cortex is involved in self-stimulation in the primate, and that the region of the orbitofrontal cortex involved in self-stimulation is the posterior orbitofrontal cortex, mainly area 13 of Walker [23].

\section{REFERENCES}

1. Bjorklund, A., I. Divac and O. Lindvall. Regional distribution of catecholamines in monkey cerebral cortex. Evidence for a dopaminergic innervation of the primate prefrontal cortex. Neurosci. Lett. 7: 115-119, 1978.

2. Ito, M. and J. Olds. Unit activity during self-stimulation behaviour. J. Neurophysiol. 34: 263-273, 1971.

3. Leonard, C. M. The prefrontal cortex of the rat. 1. Cortical projection of the mediodorsal nucleus. II. Efferent connections. Brain Res. 12: 321-343, 1969.

4. Merrill, E. G. and A. Ainsworth. Glass-coated platinum-plated tungsten microelectrodes. Med. Biol. Eng. 10: 662-672, 1972.

5. Mora, F. The Neuro-Chemical substrates of prefrontal cortex self-stimulation. A review and an interpretation of some recent data. Life Sci. 22: 919-930, 1978.

6. Mora, F., A. D. Avrith, A. G. Phillips and E. T. Rolls. Effects of satiety on self-stimulation of the orbitofrontal cortex in the rhesus monkey. Neurosci. Lett. 13: 141-145, 1979.

7. Mora, F., G. J. Mogenson and E. T. Rolls. Activity of neurones in the region of the substantia nigra during feeding. Brain Res. 133: 267-276, 1977.

8. Mora, F. and R. D. Myers. Brain self-stimulation: Direct evidence for the involvement of dopamine in the prefrontal cortex. Science 197: 1387-1389, 1977.

9. Mora, F., E. T. Rolls, M. Burton and S. G. Shaw. Effects of dopamine-receptor blockade on self-stimulation in the monkey. Pharmac. Biochem. Behav. 4: 211-216, 1976.

10. Nauta, W. J. H. Some Efferent Connections of the Prefrontal Granular Cortex and Behaviour, edited by J. M. Warren and K. Akert. New York: McGraw-Hill, 1964.

11. Rolls, E. T. Involvement of brainstem units in medial forebrain bundle self-stimulation. Physiol. Behav. 7: 297-310, 1971.
12. Rolls, E. T. The neural basis of brain-stimulation reward. Prog. Neurobiol. 3: 71-160, 1974.

13. Rolls, E. T. The Brain and Reward. Oxford: Pergamon Press, 1975.

14. Rolls, E. T. The neurophysiological basis of brain-stimulation reward. Pp. 65-87. In: Brain-stimulation Reward, edited by A. Wauquier and E. T. Rolls. Amsterdam: North-Holland, 1976, pp. 65-87.

15. Rolls, E. T., M. J. Burton and F. Mora. Hypothalamic neuronal responses associated with the sight of food. Brain Res. 111: $53-66,1976$.

16. Rolls, E. T., M. J. Burton and F. Mora. Neurophysiological analysis of brain-stimulation reward in the monkey. Brain Res. in press, 1980.

17. Rolls, E. T. and S. J. Cooper. Activation of neurones in the prefrontal cortex by brain-stimulation reward in the rat. Brain Res. 60: 351-368, 1973.

18. Rolls, E. T. and S. J. Cooper. Connection between the prefrontal cortex and pontine brain-stimulation reward sites in the rat. Expl Neurol. 42: 687-699, 1974.

19. Rolls, E. T. and S. J. Cooper. Anesthetization and stimulation of the sulcal prefrontal cortex and brain-stimulation reward. Physiol. Behav. 12: 563-571, 1974.

20. Routtenberg, A., E. L. Gardner and Y. H. Huang. Selfstimulation pathways in the monkey, Macaca Mulatta. Expl Neurol. 33: 213-224, 1971.

21. Routtenberg, A. and M. Sloan. Self-stimulation in the frontal cortex of Rattus norvegicus. Behav. Biol. 7: 567-572, 1972.

22. Snider, R. S. and J. C. Lee. A Stereotaxic Atlas of the Monkey Brain. Chicago: Univ. of Chicago Press, 1961.

23. Walker, A. E. A cytoarchitectural study of the prefrontal area of the macaque monkey. J. comp. Neurol. 73: 59-86, 1940. 